\title{
Coriandrum sativum Extract Prevents Alarm Substance-Induced Fear- and Anxiety-Like Responses in Adult Zebrafish
}

\author{
Kamila Cagliari Zenki, ${ }^{1,2}$ Lucas Santos de Souza, ${ }^{2}$ Alisson Mendonça Góis, ${ }^{2}$ Bruno dos Santos Lima, ${ }^{3}$ \\ Adriano Antunes de Souza Araújo, ${ }^{3}$ Jodnes Sobreira Vieira, ${ }^{4}$ Enilton Aparecido Camargo, ${ }^{5}$ \\ Eduardo Kalinine, ${ }^{1,5}$ Diogo Losch de Oliveira, ${ }^{1}$ and Cristiani Isabel Banderó Walker ${ }^{1,2}$
}

\begin{abstract}
Anxiety disorders appear to involve distinct neurobiological mechanisms and several medications are available against this mental health problem. However, pharmacological therapeutic approaches display undesirable side effects for patients, particularly when long-term therapy is required. Some evidences have suggested that Coriandrum sativum extract (CSE) provide sedative and anxiolytic effects. We investigate if CSE could attenuate anxiety-like behaviors induced by novelty and alarm substance exposures in zebrafish. Adult zebrafish were injected with vehicle, clonazepam, or CSE $(25,50$ or $100 \mathrm{mg} / \mathrm{kg})$ and submitted to novel tank test. At the end, saline or alarm substance was added and anxiety-like responses were recorded. Twenty-four hours after, fish were submitted to the light/dark test. Novelty associated with alarm substance exposure decreased distance traveled and total time mobile in novel tank, and CSE (at 50 and $100 \mathrm{mg} / \mathrm{kg}$ ) prevented these alterations similarly to clonazepam. Alarm substance reduced the time spent in white compartment ( $p=0.0193$ as compared with vehicle group). Clonazepam and CSE prevented this anxiogenic effect of alarm substance. CSE presents anxiolytic effects against alarm substance-induced locomotor and anxiogenic responses similarly to clonazepam. These data corroborate with the use of this plant in traditional medicine and provides a putative new pharmacological intervention for anxiety disorders.
\end{abstract}

Keywords: anxiety, zebrafish, alarm substance, Coriandrum sativum

\section{Introduction}

A NXIETY DISORDERS ARE among the most prevalent and disabling mental health conditions worldwide. ${ }^{1}$ They are considered risk factors for the development of additional mental health disorders and they are associated with an increased risk of suicide in adulthood. ${ }^{2}$ Current pharmacological anxiety treatments include the use of selective serotonin reuptake inhibitors, benzodiazepines, alpha/delta calcium channel blockers, azapirones, and beta blockers. ${ }^{3}$ Although clinical trials have showed the efficacy of the mentioned drugs, they have displayed a long list of undesirable side effects for patients, including sedation, muscle relaxation, amnesia, tolerance, and dependence, particularly when longterm therapy was required. ${ }^{4}$ These unwanted adverse effects have propelled scientists to search new chemical entities, mainly those from traditional medicine. ${ }^{5}$

In this context, several plants from different parts of the world, such as Passiflora coerulea, Matricaria recutita, Valeriana officinalis, Salvia guaranitica, Tilia europeae, and Tilia tormentosa, have been employed to discover new chemicals with putative sedative or anxiolytic effects. ${ }^{6,7}$

Another plant with reported anxiolytic and sedative effects in folk medicine is Coriandrum sativum (Apiaceae).

\footnotetext{
${ }^{1}$ Laboratory of Cellular Neurochemistry, Department of Biochemistry, Instituto de Ciências Básicas da Saúde, Universidade Federal do Rio Grande do Sul, Porto Alegre, Brazil.

${ }^{2}$ Laboratory of Neuropharmacological Studies in Zebrafish, Department of Pharmacy, Universidade Federal de Sergipe, São Cristóvão, Brazil.

${ }^{3}$ Laboratory of Pharmaceutical Trials and Toxicity, Department of Pharmacy, Universidade Federal de Sergipe, São Cristóvão, Brazil.

${ }^{4}$ Laboratory of Nutrition of Aquatic Organisms, Department of Zootechny, Universidade Federal de Sergipe, São Cristóvão, Brazil.

${ }^{5}$ Laboratory of Pharmacology of Natural Products and Inflammation, Department of Physiology, Universidade Federal de Sergipe, São Cristóvão, Brazil.
} 
Popularly known as "coentro" in Brazil and coriander in other places, $C$. sativum has been used as a culinary and medicinal plant over the years. ${ }^{8,9}$ Their leaves and seeds are widely used by folk medicine for treatment of digestive disorders, appetite loss, diabetes, and other diseases. ${ }^{8,10}$ Regarding its biological activity, this plant has hypoglycemic, anti-inflammatory, antioxidant, and antimicrobial effects. ${ }^{8,11,12}$

Moreover, other additional effects, such as hypolipidemic, antimutagenic, antihypertensive, diuretic, carminative, antispasmodic, and relaxant, were observed. ${ }^{13-20}$ In Iranian traditional medicine, the coriander aerial parts have been used for relief of anxiety and insomnia because of its sedative and hypnotic effects. ${ }^{16,21,22}$ The traditional dose of seed powder is from 1 to $5 \mathrm{~g}$, three times per day. This translates to a $14-71 \mathrm{mg} / \mathrm{kg}$ dose, three times per day. ${ }^{21,23}$ Importantly, coriander decoction to compose polyherbal traditional remedies from Ksar Lakbir district (NW Morocco) are used as neurosedative and to calm. ${ }^{24}$

On the brain, C. sativum extracts (CSEs) have been reported to exhibit sedative and anxiolytic effects. Mahendra and Bisht ${ }^{9}$ showed that hydroalcoholic extract of coriander (100 and $200 \mathrm{mg} / \mathrm{kg}$ ) produced anxiolytic effects similar to diazepam in different animal models of anxiety in mice. In addition, Emamghoreishi et al. ${ }^{16}$ and Latha et al. ${ }^{25}$ demonstrated that aqueous extract of coriander $(100$ and $200 \mathrm{mg} / \mathrm{kg}$, respectively) induced an anxiolytic activity in mice by increasing both the time spent and the percentage of entries in the open arms of elevated plus maze.

Considering the traditional use of $C$. sativum and its sedative effects reported in rodents, as also the possibility of having high amount of quercetin in coriander extracts, it has been hypothesized that CSE might also possess anxiolytic properties. Thus, the present study aimed to investigate the putative antianxiety and antistress actions of $C$. sativum hydroalcoholic leaf extract in zebrafish. For inducing anxiety and stress responses we exposed zebrafish to two distinct paradigms: novel tank test and alarm substance exposure. Novel tank test is widely used as a tool to induce anxiety responses associated to a novel environment exposure. ${ }^{26,27}$

\section{Materials and Methods}

\section{Plant collection}

C. sativum L. was collected in Aquidabã (10 $10^{\circ} 53^{\prime \prime} \mathrm{S}$ $37^{\circ} 01$ ' 07' W), Sergipe, Brazil, between June and August. A voucher specimen number ASE 35.092 was deposited at Herbarium of the Department of Botany, Federal University of Sergipe (UFS), Brazil.

\section{Extract preparation}

C. sativum fresh leaves $(282 \mathrm{~g})$ were macerated with $2 \mathrm{~L}$ of ethanol $(70 \%)$ at room temperature. Crude hydroalcoholic extract was concentrated up to dryness in a rotary evaporator (Fisatom ${ }^{\circledR}$, model 802 , Brazil) at $40^{\circ} \mathrm{C}$. The product formed was frozen at $-20^{\circ} \mathrm{C}$ for $24 \mathrm{~h}$ and lyophilized (Labconco ${ }^{\circledR}$, FreeZone 4.5 model). Total yield was $3.898 \%$.

\section{High-performance liquid chromatography analysis}

Chromatographic analysis was performed using a Shimadzu HPLC system (Shimadzu, Columbia, MD) composed of two pumps with an online degasser, an autoinjector, and a
C18 column $(4.6 \times 250 \mathrm{~mm}, 5 \mu \mathrm{m})$ coupled to a DAD-UV/Vis detector. Sample volume of $20 \mu \mathrm{L}(1 \mathrm{mg} / \mathrm{mL})$ was dissolved in HPLC grade methanol and subjected to gradient elution with mobile phases consisting of water and methanol from $5 \%$ to $100 \%$ during $60 \mathrm{~min}$ in a wavelength range from 220 to $400 \mathrm{~nm}$. Shimadzu LC Solution software (Kyoto, Japan) was used for data acquisition. Identification of the compounds was performed with the coinjection of standard secondary metabolites, according with their retention time (RT) and UV spectra. Gallic acid $\left(\mathrm{C}_{7} \mathrm{H}_{6} \mathrm{O}_{5}\right)$, caffeic acid $\left(\mathrm{C}_{9} \mathrm{H}_{8} \mathrm{O}_{4}\right)$, luteolin $\left(\mathrm{C}_{15} \mathrm{H}_{10} \mathrm{O}_{6}\right)$, quercetin 3- $\beta$-D-glucoside $\left(\mathrm{C}_{21} \mathrm{H}_{20} \mathrm{O}_{12}\right)$, and rutin $\left(\mathrm{C}_{27} \mathrm{H}_{30} \mathrm{O}_{16}\right)$, were obtained from Sigma-Aldrich ${ }^{\circledR}$ and diluted with methanol (see chromatogram in Fig. 1). To calculate the concentration of each secondary metabolite, calibration curves for each compound were performed with five different concentrations ranging from 1 to $50 \mu \mathrm{g} / \mathrm{mL}$. Analyzes were performed in triplicate $(n=3)$.

\section{Animals and treatments}

A total of 105 male adult zebrafish (Danio rerio) (short fin wild-type strain; 4-6 months old) were used in the present work. They were obtained from a local commercial supplier (Aquazoo, SE, Brazil) and were acclimated for at least 2 weeks prior the experiments. Animals were maintained in "home tanks," which consisted in $20 \mathrm{~L}$ aerated tanks (three animals/L) filled with distilled water under mechanical and chemical filtration. Water temperature, $\mathrm{pH}$, and conductivity were adjusted to $26^{\circ} \mathrm{C} \pm 2^{\circ} \mathrm{C}, 7.0-8.0$, and $500 \mu \mathrm{S}$, respectively.

Ceiling-mounted fluorescent white lamps provided room illumination (600 lux). Light/dark cycle was 12/12 h (lights on at 7:00 am). Only animals weighing between 0.25 and $0.35 \mathrm{~g}$ were used. All animals were fed four times a day with ALCON BASIC ${ }^{\mathrm{TM}}$ flake food (ALCON, Brazil; twice a day) and Artemia sp. nauplii (twice a day). All procedures were performed according to the Brazilian's Law for Care and Use of Laboratory Animals (Law 11794/2008) and previously approved by the Animal Research Ethics Committee from UFS/Brazil (protocol number 37/2015).

Alarm substance extraction. Alarm substance was extracted as described previously. ${ }^{28-30}$ One set of zebrafish (five animals that were not used for behavioral analysis) were cold anesthetized and quickly euthanized by decapitation. Alarm substance was extracted performing fifteen superficial cuts in the skin of animals and then washed with saline solution (10 $\mathrm{mL} / \mathrm{animal})$. During the extraction and further use, alarm substance solution was kept on ice, at $4^{\circ} \mathrm{C}$.

Drug administration. Another set of animals ( $n=100$ animals) were anesthetized by tricaine immersion $(160 \mu \mathrm{g} / \mathrm{mL})^{31}$ and further injected i.p. with CSE $(25,50$ or $100 \mathrm{mg} / \mathrm{kg})$, or clonazepam $(0.05 \mathrm{mg} / \mathrm{kg})$ or vehicle (20 animals/group). The maximal volume of injection was $10 \mu \mathrm{L} / \mathrm{g}$ of body mass. ${ }^{32}$ Immersion in tricaine lasted 1-2 min, until fish were completely immobile and decreased opercular opening. Vehicle was composed of $40 \%$ propylene glycol, $10 \%$ ethyl alcohol, $5 \%$ sodium benzoate, and $1.5 \%$ benzyl alcohol. ${ }^{33,34}$ Drugs were administered $30 \mathrm{~min}$ before the behavioral evaluations. ${ }^{9}$ 
FIG. 1. Chromatogram of a fresh leaf aqueous alcoholic extract ( $70 \%$ ethanol) from Coriandrum sativum after lyophilization.

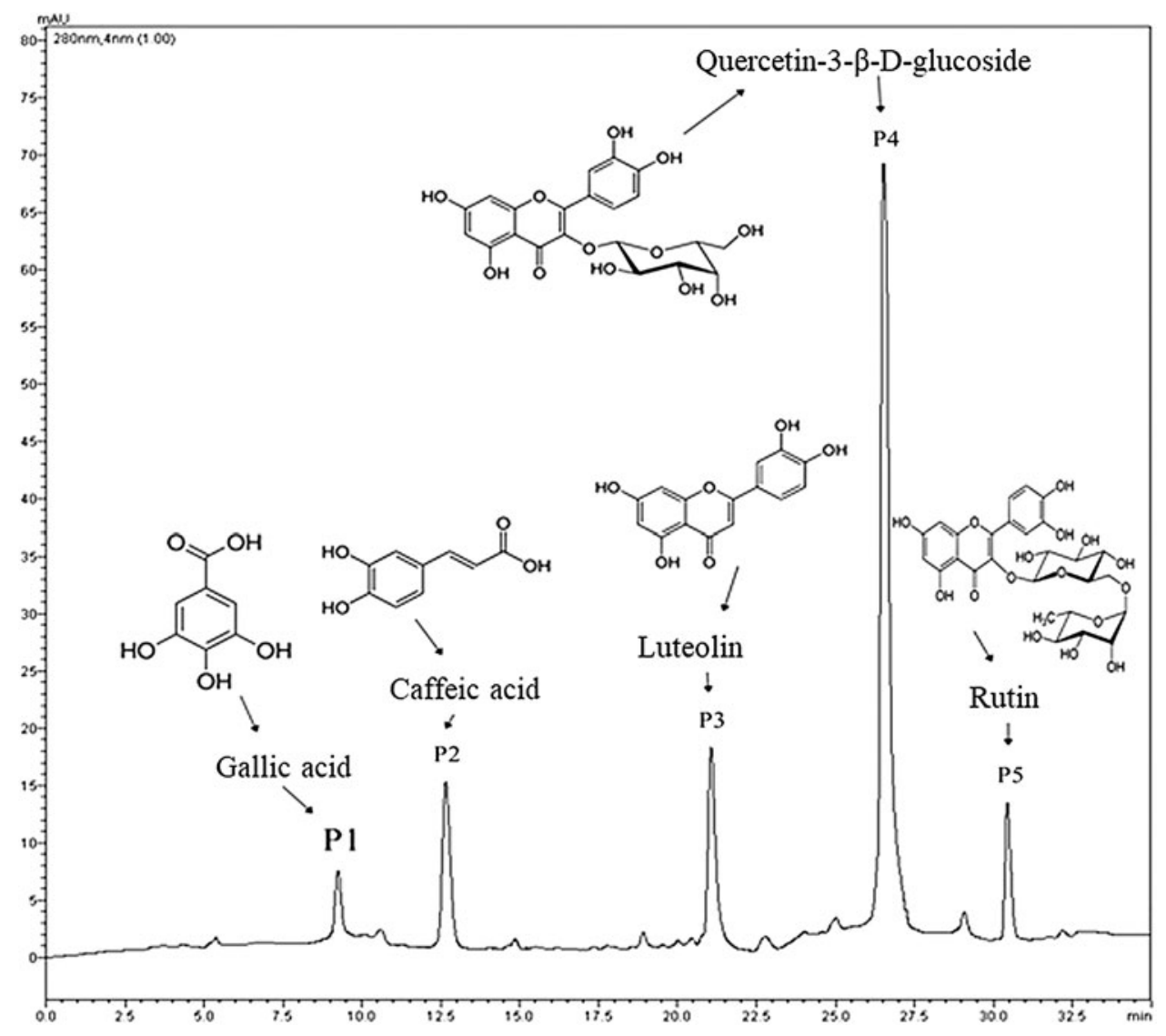

\section{Behavioral procedures and alarm substance exposure}

All behavioral tests were performed between 9:00 a.m. and 4:00 p.m. Behavioral analysis was conducted as depicted in Figure 2. Animals treated with vehicle, clonazepam, or CSE were submitted to novel tank test for $6 \mathrm{~min}$. At the end of the novel tank test, animals were exposed to alarm substance. Without removing animals from the novel tank apparatus, alarm substance $(3.5 \mathrm{~mL}$ of skin washout/L) or saline solution were carefully delivered in the tank through a syringe connected to a polypropylene tube ( $n=10$ animals for each group).

Swimming behavior was recorded for additional $6 \mathrm{~min}$. After this period, fish were removed from the novel tank apparatus and placed, in pairs, in 1.5-L tanks until the beginning of the light/dark test. This strategy was used for keeping all experimental groups for the same time period of $24 \mathrm{~h}$ until the beginning of light/dark test. All behavioral tests were conducted under white illumination (800 lux of intensity). Behavioral analysis was performed in four independent experiments (25 animals/experiment). Animals were randomly distributed in each experiment as well as in experimental group by using an online tool for randomization (www.randomizer.org).

Novel tank test. Novel tank consisted of a 1.5-L trapezoidal tank $(23.9 \mathrm{~cm}$ along the bottom $\times 28.9 \mathrm{~cm}$ at the top $\times$ $15.1 \mathrm{~cm}$ high $\times 15.9 \mathrm{~cm}$ along the diagonal side) similar to those previously described by Rosemberg et al. ${ }^{35}$ Tank was filled with $1.5 \mathrm{~L}$ home-tank water and was divided in three equally virtual horizontal areas (named bottom, middle, and top). The following behavioral variables were evaluated: total time mobile (s), distance travelled (m), total time spent (s) in bottom, middle, and top areas. A video camera located $\sim 40 \mathrm{~cm}$ ahead the tank was used to monitor the activity of fish. ANY-Maze ${ }^{\circledR}$ software was used to track the swimming pattern of fish. Immobility was previously defined as the absence of movement or fish moving slower than $1 \mathrm{~cm} / \mathrm{s}$.

Light/dark test. The light/dark test was performed accordingly to Maximino et al. ${ }^{33}$ with modifications. Apparatus consisted of a tank $(15 \times 10 \times 45 \mathrm{~cm}$, height $\times$ depth $\times$ length $)$ equally divided into two distinct compartments (one black and other white covered). Opaque plastic self-adhesive films were used for covering walls and floor of both compartments. Apparatus was filled with $1.5 \mathrm{~L}$ home-tank water. Animals were individually placed in the lit area of the tank and were allowed to explore the apparatus for $15 \mathrm{~min}$. The following behavioral parameters were recorded: number of entries and time spent in each compartment, and number of risk assessment behaviors. Risk assessment behaviors were defined as a partial entry in the white compartment followed by a fast return to the dark one. ${ }^{36}$

\section{Statistical analysis}

Data were expressed as mean \pm standard deviation. All data were first tested for normality by D'Agostino-Pearson omnibus normality test. Basal novel tank data were analyzed by one-way ANOVA followed by Tukey's post hoc test. Behavioral data from light/dark test and alarm substance exposure were analyzed by two-way ANOVA followed by Sidak's post hoc test. For each data, Cohen's $d$ was shown as 


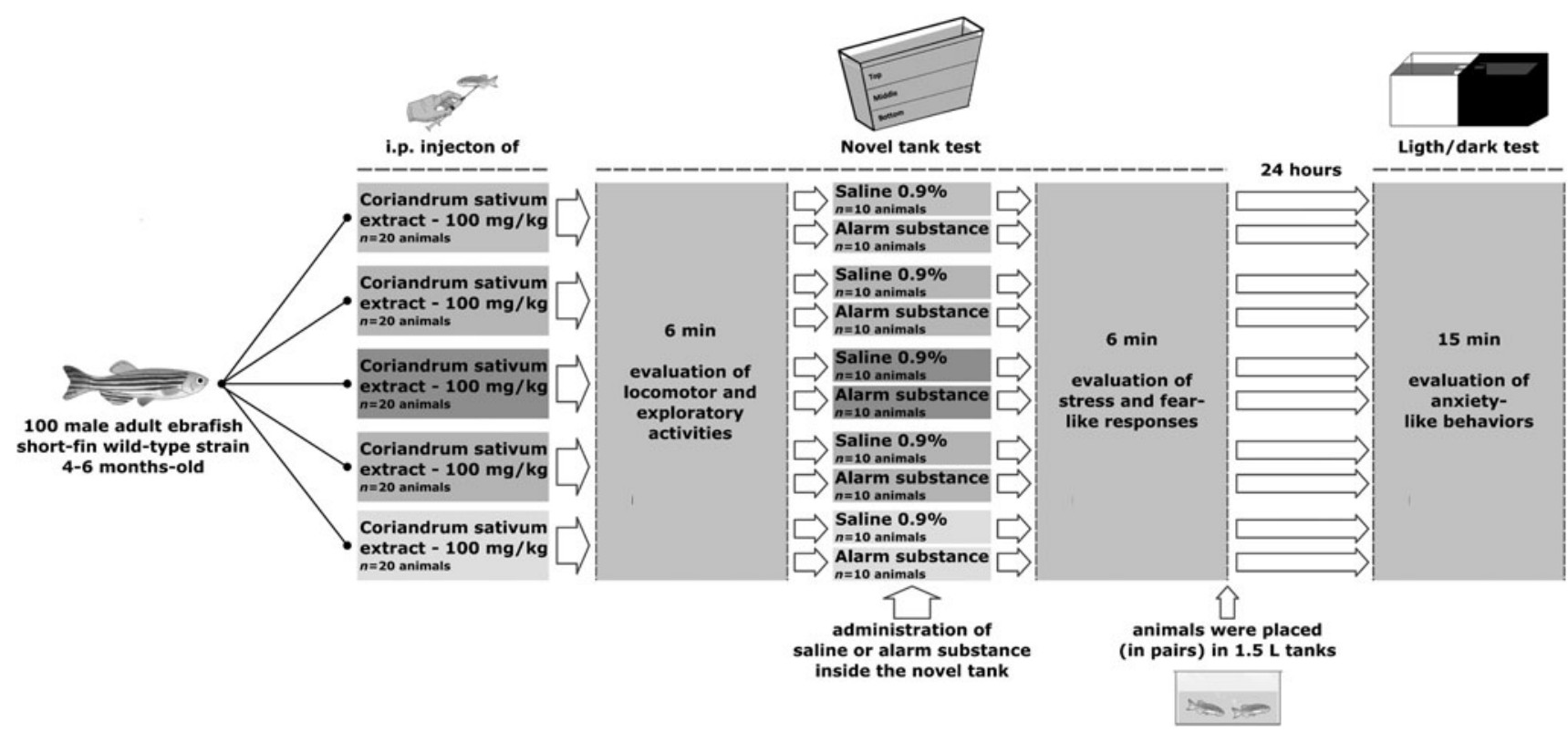

FIG. 2. Diagram illustrating the experimental design. After acquisition, animals were acclimated for 2 weeks before the beginning of the experiments. Animals were injected with vehicle, clonazepam, or CSE and were submitted to novel tank test for evaluating the basal locomotor and exploratory activities. At the end of novel tank test, saline or alarm substance were added to the tank and the locomotor and anxiety-like responses were recorded during $6 \mathrm{~min}$. After this period, animals returned in pairs to the home-tank. Twenty-four hours after, fish were submitted to the light/dark test. CSE, Coriandrum sativum extract.

Cumming estimation plot. The raw data were plotted on the upper axes of figures; each mean difference was plotted on the lower axes of figures as a bootstrap sampling distribution. Mean differences are depicted as dots; $95 \%$ confidence intervals are indicated by the ends of the vertical error bars. $p \leq 0.05$ was considered significant.

\section{Results}

\section{HPLC characterization of CSE}

Chromatographic profile of the CSE was shown in Figure 1. Fractions P1 (RT: $9.16 \mathrm{~min}), \mathrm{P} 2$ (RT: $12.58 \mathrm{~min}), \mathrm{P} 3$ (RT: $21.09 \mathrm{~min}), \mathrm{P} 4$ (RT: $26.49 \mathrm{~min})$, and P5 (RT: $30.37 \mathrm{~min}$ ), were
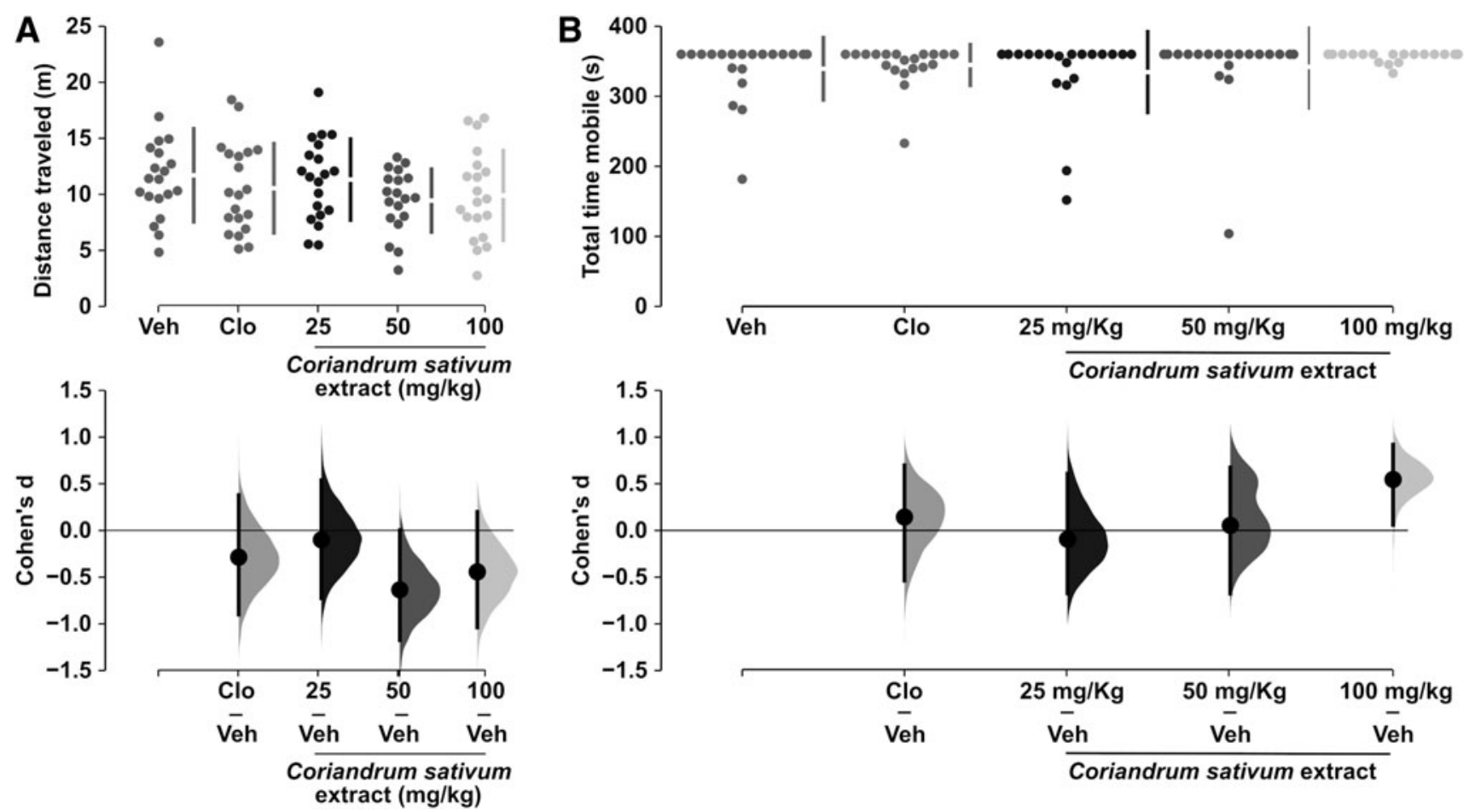

FIG. 3. Baseline locomotor profile of fish treated with vehicle, clonazepam or CSE; $n=20$ animals/group. (A) Total distance travelled $(\mathrm{m})$ in apparatus during $6 \mathrm{~min}$ of trial; (B) Total mobile time (s) during $6 \mathrm{~min}$. Data expressed as mean \pm standard deviation (one-way ANOVA followed by Tukey’s post hoc test). 

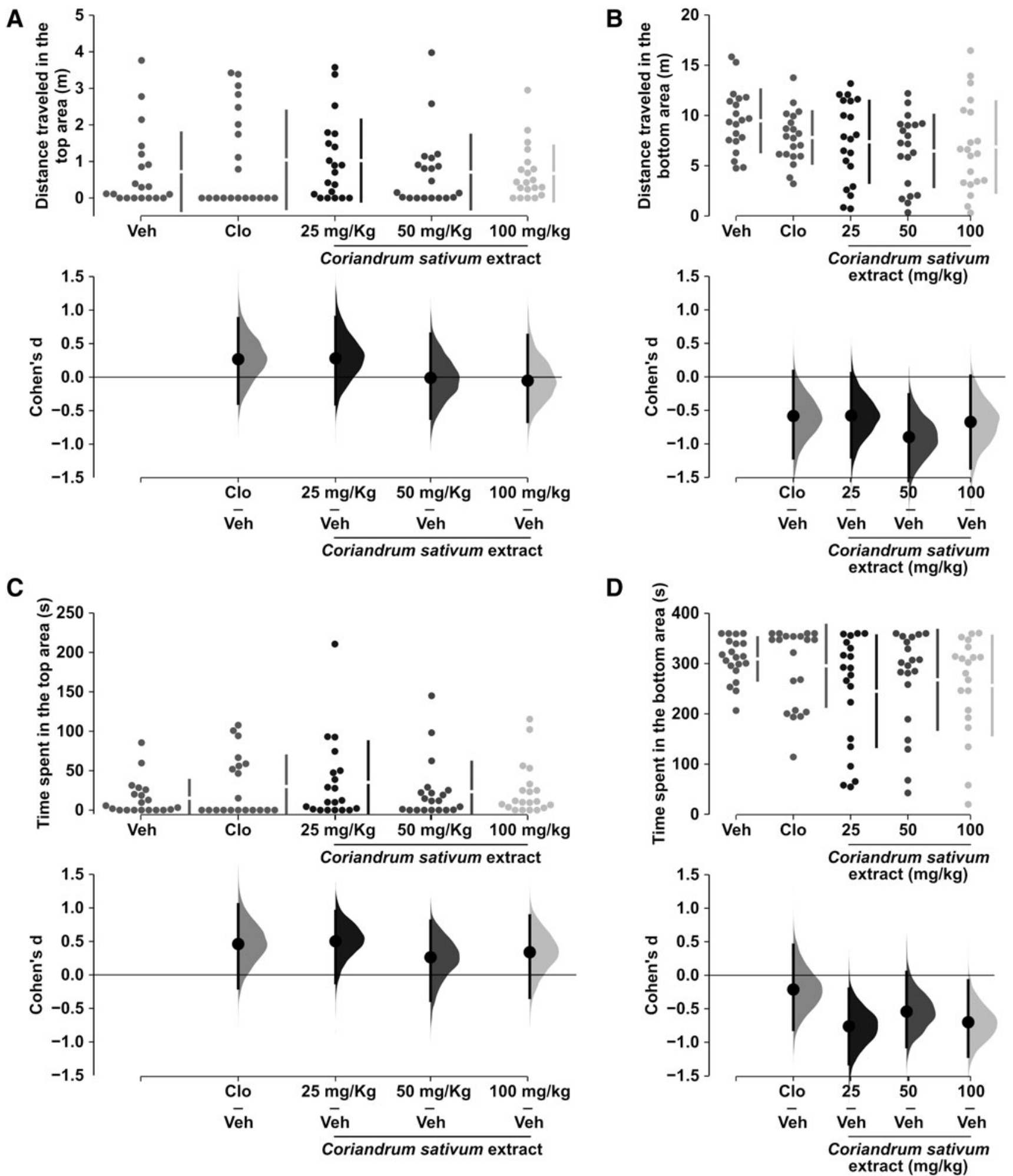

FIG. 4. Baseline exploratory profiles into two horizontal portions of the apparatus: (A) Total distance travelled in top area (m); (B) Total distance travelled in bottom area (m); (C) Total time spent in top area (s); (D) Total time spent in bottom area (s) of fish treated with vehicle, clonazepam, or CSE. $n=20$ animals/group. Data expressed as mean \pm standard deviation (one-way ANOVA followed by Tukey's post hoc test). 
identified as gallic acid, caffeic acid, luteolin, quercetin 3- $\beta$ D-glucoside, and rutin, respectively. Quantitative analysis was obtained by using calibration curves of each secondary metabolite. All curves showed a correlation coefficient of $r \geq 0.999$. Concentrations of $\mathrm{P} 1, \mathrm{P} 2, \mathrm{P} 3, \mathrm{P} 4$, and $\mathrm{P} 5$ were 1.88 , $2.32,5.61,43.56$, and $3.21 \mu \mathrm{g} / \mathrm{mL}$, respectively.

\section{Effect of CSE on alarm substance-induced alterations in locomotor and exploratory activities}

Baseline locomotor and exploratory activities did not differ among experimental groups (Figs. 3-5). Animals spent more time in the bottom area. Clonazepam or CSE administration did not alter distance traveled or time spent in homebase area when compared with control group, suggesting a classical homebase formation (Fig. 5). In control groups, alarm substance exposure reduced distance traveled and total time mobile (Fig. 6A $F[1,90]=7.638$ and $\mathrm{B} F[1,90]=3.997 ; p=0.0257$ and 0.0343 , respectively). To distance parameter, the unpaired Cohen's $d$ between vehicle-saline and vehicle-alarm is -1.27 [95.0\% CI $-2.55,-0.242]$. The two-sided $p$ value of the Mann-Whitney test is 0.0257 ; the unpaired Cohen's $d$ between clonazepamsaline and clonazepamalarm is -0.512 [95.0\% CI $-1.45,0.454]$. The two-sided $p$ value of the Mann-Whitney test is 0.273 ; the unpaired Cohen's $d$ between $25 \mathrm{mg} / \mathrm{kg}$-saline and $25 \mathrm{mg} / \mathrm{kg}$-alarm is -1.5 [95.0\% CI $-2.6,-0.368]$. The two-sided $p$ value of the Mann-Whitney test is 0.00911 ; the unpaired Cohen's $d$ between $50 \mathrm{mg} / \mathrm{kg}$-saline and $50 \mathrm{mg} / \mathrm{kg}$-alarm is 0.0705 [95.0\% CI $-0.864,1.0]$. The two-sided $p$ value of the Mann-Whitney test is
0.734; the unpaired Cohen's $d$ between $100 \mathrm{mg} / \mathrm{kg}$-saline and $100 \mathrm{mg} / \mathrm{kg}$-alarm is 0.0891 [95.0\% CI $-0.862,1.0]$. The twosided $p$ value of the Mann-Whitney test is 0.734 .

Only treatment with $25 \mathrm{mg} / \mathrm{kg}$ of CSE $(p=0.0322)$ did not prevent the alarm substance-induced behavioral changes. In contrast, 50 and $100 \mathrm{mg} / \mathrm{kg}$ of CSE prevented the reduction in distance travelled and total time mobile induced by alarm substance (Fig. 6A, B, respectively). There was no difference between groups regarding distance traveled and time spent in top and bottom areas (Fig. 7). Although distance traveled in top area was not different among groups, alarm substance exposure appears to reduce suddenly the distance traveled in vehicle group ( $p=0.2621)$ (Fig. 7A).

\section{Effect of CSE on anxiety-like behaviors}

Alarm substance exposure reduced the time spent in white compartment when compared with fish from saline group $(p=0.0193)$. Treatment with clonazepam and CSE in all tested concentrations prevented this reduction (Fig. 8A; $F[1,90]=5.514)$. The unpaired Cohen's $d$ between vehiclesaline and vehicle-alarm is -1.35 [95.0\% CI $-2.53,-0.2]$. The two-sided $p$ value of the Mann-Whitney test is 0.0173 ; the unpaired Cohen's $d$ between clonazepam-saline and clonazepam-alarm is 0.704 [95.0\% CI $-0.236,1.78]$. The two-sided $p$ value of the Mann-Whitney test is 0.186 ; the unpaired Cohen's $d$ between $25 \mathrm{mg} / \mathrm{kg}$-saline and $25 \mathrm{mg} / \mathrm{kg}$ alarm is -2.06 [95.0\% CI $-2.98,-1.03]$. The two-sided $p$ value of the Mann-Whitney test is 0.00131 ; the unpaired
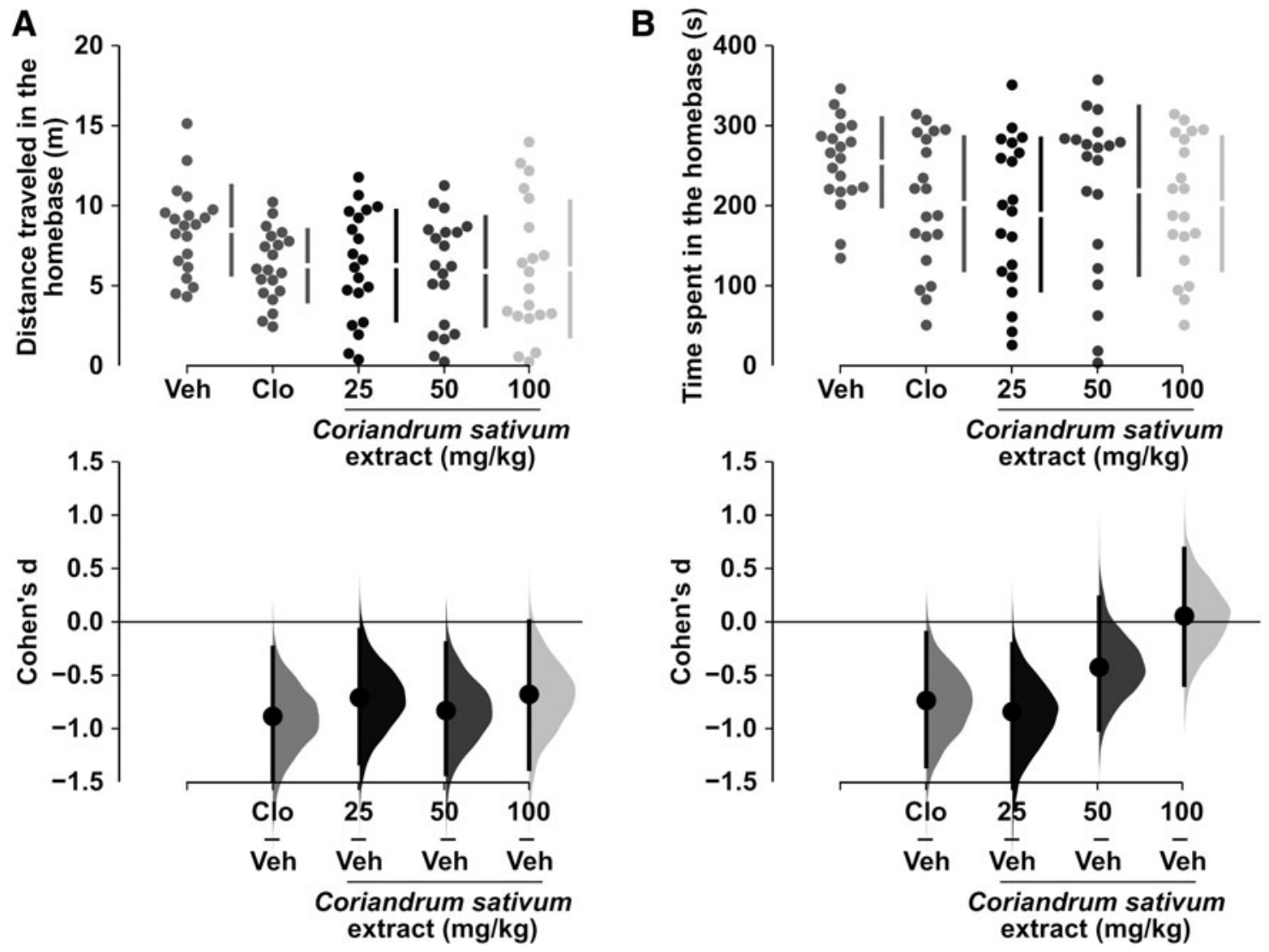

FIG. 5. Locomotor profiles in homebase area of fish treated with vehicle, clonazepam or CSE. (A) Total distance traveled and (B) total time spent in the home base area. $n=20$ animals/group. Data expressed as mean \pm standard deviation (one-way ANOVA followed by Tukey's post hoc test). Data expressed as mean \pm standard deviation. 


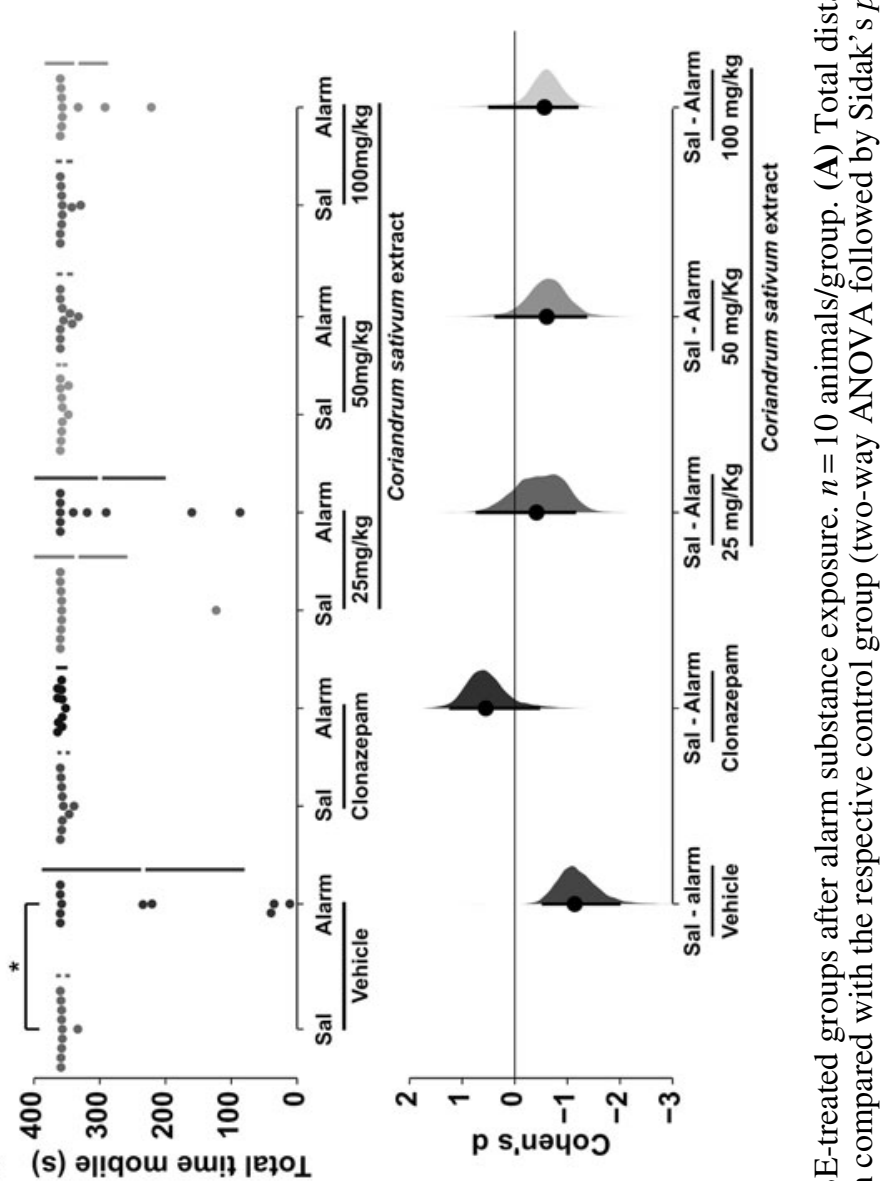

m (s) 키qou әu!? |eł।

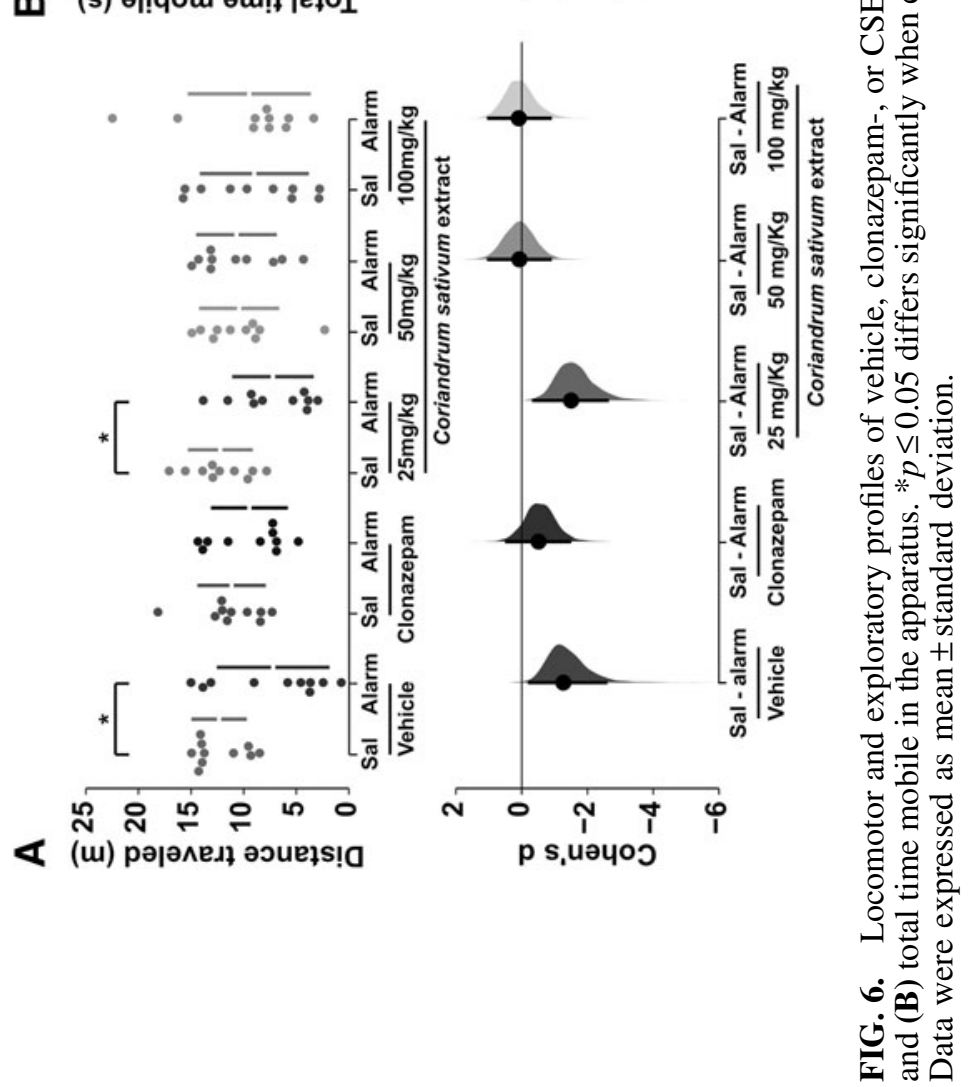



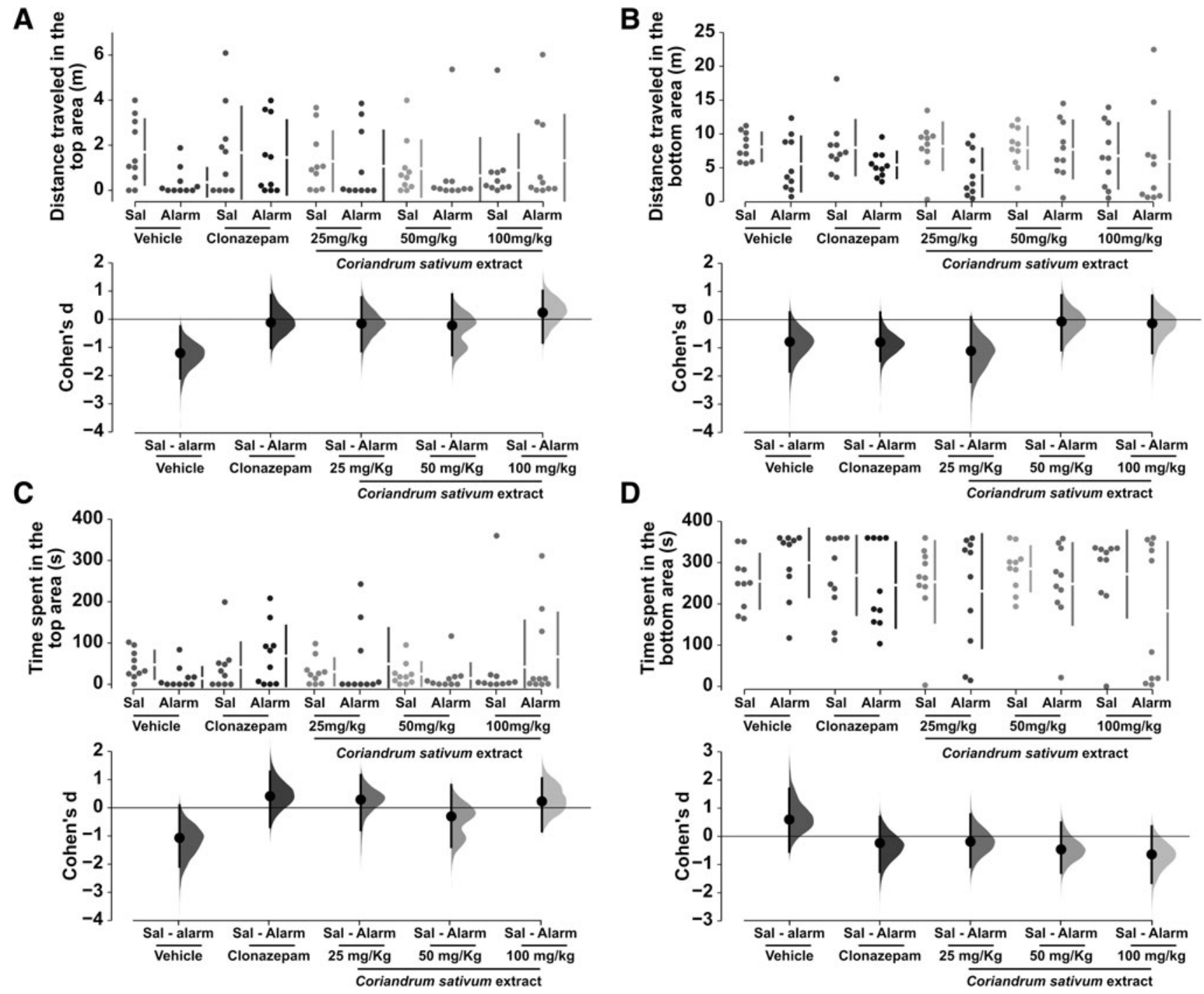

FIG. 7. Locomotor and exploratory profiles of vehicle, clonazepam-, or CSE-treated groups after alarm substance exposure. $n=10$ animals per group. (A) Total distance traveled in the top area; (B) total distance traveled in the top bottom; (C) total time spent in the top area; and (D) total time spent in the top area of the apparatus. Data are expressed as mean \pm standard deviation and were analyzed by two-way ANOVA followed by Sidak's post hoc test.

Cohen's $d$ between $50 \mathrm{mg} / \mathrm{kg}$-saline and $50 \mathrm{mg} / \mathrm{kg}$-alarm is $-0.253[95.0 \% \mathrm{CI}-1.22,0.736]$. The two-sided $p$ value of the Mann-Whitney test is 0.623; the unpaired Cohen's $d$ between $100 \mathrm{mg} / \mathrm{kg}$-saline and $100 \mathrm{mg} / \mathrm{kg}$-alarm is $-0.498[95.0 \% \mathrm{CI}$ $-1.39,0.489]$. The two-sided $p$ value of the Mann-Whitney test is 0.345 .

Moreover, alarm substance induced a significant increase in the risk assessment behaviors in animals treated with vehicle $(p<0.0001)$ and clonazepam $(p=0.0173)$. There was no difference in risk assessment behaviors in CSE-treated animals (Fig. 8C; $F[1,90]=5.514$ ). The unpaired Cohen's $d$ between vehicle-saline and vehicle-alarm is 6.6 [95.0\% CI 4.81, 8.81]. The two-sided $p$ value of the Mann-Whitney test is 0.000176 ; the unpaired Cohen's $d$ between clonazepam-saline and clonazepam-alarm is 1.43 [95.0\% CI $0.667,2.31]$. The twosided $p$ value of the Mann-Whitney test is 0.009 ; the unpaired Cohen's $d$ between $25 \mathrm{mg} / \mathrm{kg}$-saline and $25 \mathrm{mg} / \mathrm{kg}$-alarm is 0.688 [95.0\% CI $-0.293,1.72]$. The two-sided $p$ value of the Mann-Whitney test is 0.0818; the unpaired Cohen's $d$ between $50 \mathrm{mg} / \mathrm{kg}$-saline and $50 \mathrm{mg} / \mathrm{kg}$-alarm is 0.751 [95.0\% CI
$-0.211,1.46]$. The two-sided $p$ value of the Mann-Whitney test is 0.172; The unpaired Cohen's $d$ between $100 \mathrm{mg} / \mathrm{kg}$-saline and $100 \mathrm{mg} / \mathrm{kg}$-alarm is 0.944 [95.0\% CI $-0.158,1.85]$. The two-sided $p$ value of the Mann-Whitney test is 0.0885 . The number of crossing was not altered in any groups (Fig. 8B).

\section{Discussion}

To evaluate the locomotor and exploratory activities in fish treated with CSE, we tested it at concentrations ranging from 25 to $100 \mathrm{mg} / \mathrm{kg}$. After treatments, animals performed novel tank test before (baseline) and after (post stress) saline or alarm substance exposure. We observed that CSE-treated animals did not present alterations in baseline behavior. In the present study motor and nonmotor patterns associated with anxiety-like behaviors after stressful paradigm were analyzed, to investigate the putative CSE anxiolytic effect. In poststress session, total distance traveled and total time mobile decreases after alarm substance administration when compared with saline administration in vehicle-treated animals, 
whereas treatment with clonazepam and CSE (50 and $100 \mathrm{mg} / \mathrm{kg}$ ) did not alter this parameter. We also found that acute exposure to alarm substance inhibited transitions to the top of the tank. These data corroborate with previous findings in which alarm substance exposure disrupts rapid habituation response of zebrafish in the novel tank test ${ }^{37}$ and suggest that alarm substance is effective in inducing fear responses in zebrafish. ${ }^{28}$ Thus, CSE-treated animals presented an anxiolytic response similar to clonazepam-treated animals into stressful paradigm used in the present study.

Situations like threat or danger cause fear and/or anxiety that may elicit innate defensive behaviors. Pharmacological studies show that alarm substance released from injured skin cells may elicit defensive behaviors characterized by increased speed of movement, erratic movements, freezing bouts, and agglomeration in the bottom zone of the tank. ${ }^{27,28,30,38,39}$ Therefore, decrease in movement observed in the poststress session in novel tank may be related to alarm substance exposure added to new environment interaction, considering that first novel tank session provides a stressor stimulus.

In fact, besides alarm substance exposure, we explore the novel tank test to propitiate stressful condition, because it is known as a novel tank that is being utilized as a tool to reveal the animal's interaction with a novel environment. ${ }^{26,27}$ Several studies justified this test as a model of anxiety based on the animal's natural instinct to seek protection in an unfamiliar environment presented exploration, freezing, or immobility and top entries, ${ }^{26,29,40}$ and it is a behavioral tool that is used to measure novelty-associated behavioral stress responses. ${ }^{41}$

To confirm the anxiolytic action of CSE demonstrated in novel tank test, we evaluated the light/dark test. It has been used as an anxiety test and anxiolytic drugs have been found to increase the time spent in the light zone, whereas anxiogenic drugs decreased it. ${ }^{33,34,42}$ We demonstrated for the first time that novel tank associated with alarm substance administration produces an anxiogenic effect that persists during $24 \mathrm{~h}$. Importantly, CSE and clonazepam administration provide a control of this long-term behavior alteration. Our results demonstrated that CSE prevents anxiety-like phenotype produced by novelty response associated to alarm substance exposure, as well as exploratory and locomotor influences produced by acute alarm substance administration.

C. sativum, popularly known as "coentro" or coriander, is traditionally used for gastrointestinal and cardiovascular disorders. ${ }^{43}$ Additionally, some evidence supports this plant use in convulsions, anxiety, insomnia, because of its sedative property. ${ }^{16,17,44}$ Also, in the Indian traditional medicine, it is used in the disorders of digestive, respiratory, and urinary systems, as it has diaphoretic and diuretic effects. ${ }^{9}$

Several compounds have been isolated from coriander oil, such linalool, $\alpha$-pirene, $\gamma$-terpinene, geranyl acetate, camphor,

FIG. 8. Anxiety-like behavioral profile of vehicle, clonazepam, or CSE-treated groups after alarm substance exposure. (A) Total time spent in the white compartment of black/white apparatus; (B) number of risk assessment behaviors; and (C) number of crossings between white and black compartment. $n=10$ animals per group. ${ }^{*} p \leq 0.05$ and $* * * p \leq 0.0001$ differs significantly when compared with respective to control group (two-way ANOVA followed by Sidak's post hoc test). and geraniol, ${ }^{14,15}$ although many biologically active compounds are also soluble in water. ${ }^{45} \mathrm{CSE}$ was characterized for LC-MS screening, which revealed the presence of a high amount of quercetin. There are several studies, which have shown that quercetin produces a variety of anxiolytic-like behavioral effects. ${ }^{46-48}$ Nevertheless, it has been reported that
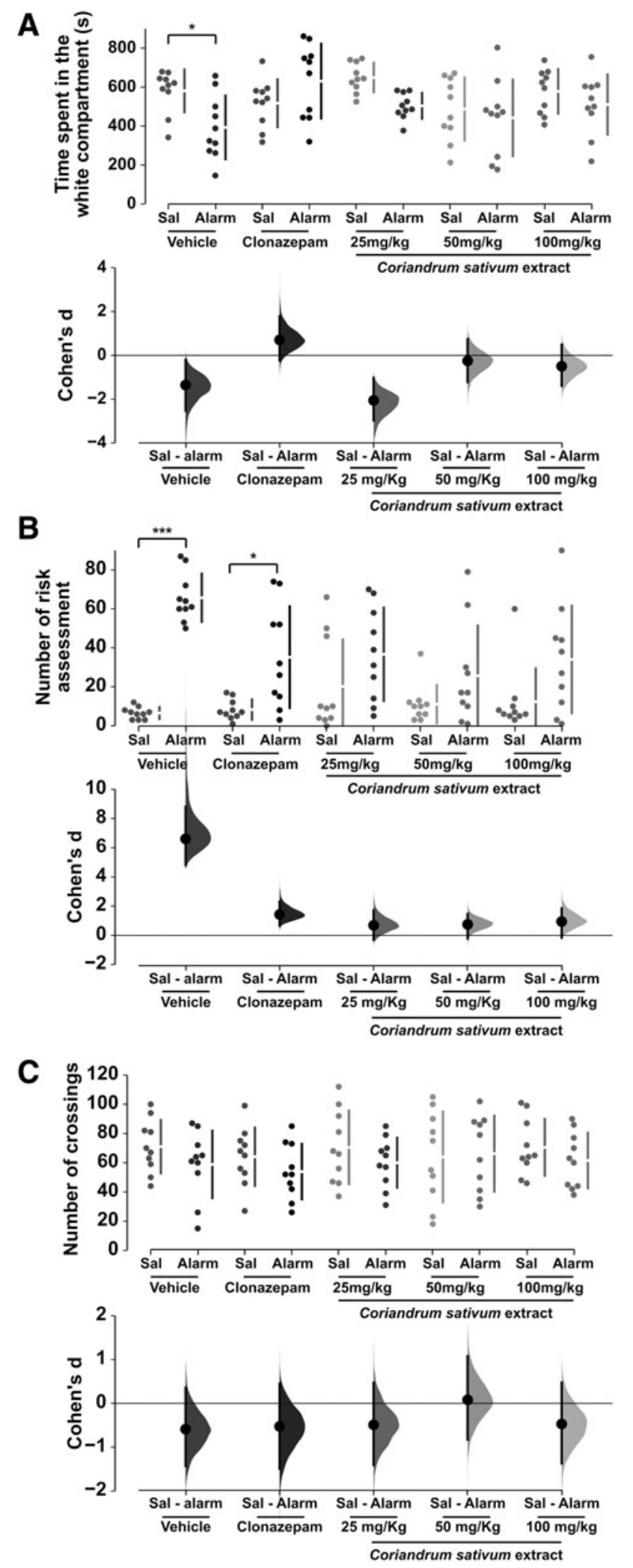
quercetin present good potential to reduce stress, decreased plasma cortisol levels, and improve memory performance..$^{49,50}$ Moreover, quercetin could prevent the impairment of the enzymes that regulate the purinergic and cholinergic extracellular signaling as adenosine deaminase and acetylcholinesterase improving the memory and anxiety-like behavior induced by streptozotocin-induced diabetic rats. ${ }^{51}$ Taken together, these results may suggest that quercetin might be responsible for improving behavioral dysfunction during anxiety episodes. Although quercetin is the major compound in CSE, its anxiolytic effect is probably related to polyphenol mixture, considering the potential of these compounds for modulation of the anxiety-like phenotype. ${ }^{52,53}$

In the present work, treatment with clonazepam prevented the alarm substance-induced decrease in time spent in white compartment. Another study demonstrated a similar result for clonazepam $(0.3 \mathrm{mg} / \mathrm{L})$ in light/dark test. ${ }^{42}$ Studies verified that treatment with anxiolytic drugs as fluoxetine, clonazepam, buspirone, and ethanol reduced fear- and anxiety-like behavior. $^{34,40,42}$ Doses of CSE administrated in this work did not alter the number of crossing responses in the light/dark test, suggesting a potential anxiolytic effect without producing effects on locomotion. Indeed, vehicle- and clonazepam-treated animals increased the number of risk assessment episodes, whereas CSE prevent this effect in the light/dark test. This parameter indicates a potential anxiolytic activity to CSE. Due to this, CSE represents a new potential candidate for treatment of anxiety disorders without producing effects on locomotion.

\section{Conclusion}

Our findings suggest that long-term anxiety behavior may be achieved using a combination of novelty response in novel tank and alarm substance exposure in zebrafish. In this approach, CSE promoted anxiolytic effect. Thus, this work assists in the efficacy confirmation of this plant used in traditional medicine and can provide a new pharmacological intervention in anxiety disorders.

\section{Disclosure Statement}

No competing financial interests exist.

\section{Funding Information}

This work was supported by Conselho Nacional de Desenvolvimento Científico e Tecnológico (CNPq), Coordenação de Aperfeiçoamento de Pessoal de nível Superior (CAPES), FAPERGS/PRONEX edital no. 16/2551-0000499-4, CNPq Edital Doenças Neurodegenartivas no. 467676/2014-3.

\section{References}

1. Spinhoven P, Batelaan N, Rhebergen D, van Balkom A, Schoevers R, Penninx BW. Prediction of 6-yr symptom course trajectories of anxiety disorders by diagnostic, clinical and psychological variables. J Anxiety Disord 2016;44:92-101.

2. Gross C, Hen R. The developmental origins of anxiety. Nat Rev Neurosci 2004;5:545-552.

3. Farach FJ, Pruitt LD, Jun JJ, Jerud AB, Zoellner LA, RoyByrne PP. Pharmacological treatment of anxiety disorders: current treatments and future directions. J Anxiety Disord 2012;26:833-843.

4. Huh J, Goebert D, Takeshita J, Lu BY, Kang M. Treatment of generalized anxiety disorder: a comprehensive review of the literature for psychopharmacologic alternatives to newer antidepressants and benzodiazepines. Prim Care Companion CNS Disord 2011;13.

5. Farzaei MH, Bahramsoltani R, Rahimi R, Abbasabadi F, Abdollahi M. A systematic review of plant-derived natural compounds for anxiety disorders. Curr Top Med Chem 2016;16:1924-1942.

6. McIntyre E, Saliba AJ, Wiener KK, Sarris J. Herbal medicine use behaviour in Australian adults who experience anxiety: a descriptive study. BMC Complement Altern Med 2016;16:60.

7. Gomes NG, Campos MG, Orfao JM, Ribeiro CA. Plants with neurobiological activity as potential targets for drug discovery. Prog Neuropsychopharmacol Biol Psychiatry 2009;33:1372-1389.

8. Laribi B, Kouki K, M'Hamdi M, Bettaieb T. Coriander (Coriandrum sativum L.) and its bioactive constituents. Fitoterapia 2015;103:9-26.

9. Mahendra P, Bisht S. Anti-anxiety activity of Coriandrum sativum assessed using different experimental anxiety models. Indian J Pharmacol 2011;43:574-577.

10. Helm J, Hanelt P. [The "Herb Book" by Johannes Kentmann of 1563]. Sudhoffs Arch 1971;13:Suppl 13:89-21.

11. Prachayasittikul V, Prachayasittikul S, Ruchirawat S. Coriander (Coriandrum sativum): a promising functional food toward the well-being. Food Res Int 2018;105:305-323.

12. Pellegrini M, Ricci A, Serio A, Chaves-Lopez C, Mazzarrino G, D'Amato S, et al. Characterization of essential oils obtained from abruzzo autochthonous plants: antioxidant and antimicrobial activities assessment for food application. Foods 2018;7.

13. Anaeigoudari A, Hosseini M, Karami R, Vafaee F, Mohammadpour T, Ghorbani A, et al. The effects of different fractions of Coriandrum sativum on pentylenetetrazoleinduced seizures and brain tissues oxidative damage in rats. Avicenna J Phytomed 2016;6:223-235.

14. Caputo L, Souza LF, Alloisio S, Cornara L, De Feo V. Coriandrum sativum and Lavandula angustifolia essential oils: chemical composition and activity on central nervous system. Int J Mol Sci 2016;17.

15. Cioanca O, Hritcu L, Mihasan M, Trifan A, Hancianu M. Inhalation of coriander volatile oil increased anxiolyticantidepressant-like behaviors and decreased oxidative status in beta-amyloid (1-42) rat model of Alzheimer's disease. Physiol Behav 2014;131:68-74.

16. Emamghoreishi M, Khasaki M, Aazam MF. Coriandrum sativum: evaluation of its anxiolytic effect in the elevated plus-maze. J Ethnopharmacol 2005;96:365-370.

17. Gaston MS, Cid MP, Vazquez AM, Decarlini MF, Demmel GI, Rossi LI, et al. Sedative effect of central administration of Coriandrum sativum essential oil and its major component linalool in neonatal chicks. Pharm Biol 2016;54:1954-1961.

18. Hajhashemi V, Safaei A. Hypnotic effect of Coriandrum sativum, Ziziphus jujuba, Lavandula angustifolia and Melissa officinalis extracts in mice. Res Pharm Sci 2015;10:477-484.

19. Karami R, Hosseini M, Mohammadpour T, Ghorbani A, Sadeghnia HR, Rakhshandeh H, et al. Effects of hydroalcoholic extract of Coriandrum sativum on oxidative damage in pentylenetetrazole-induced seizures in rats. Iran J Neurol 2015;14:59-66.

20. Liu QF, Jeong H, Lee JH, Hong YK, Oh Y, Kim YM, et al. Coriandrum sativum suppresses a $\beta \beta 42$-induced ROS increases, glial cell proliferation, and ERK activation. Am J Chin Med 2016;44:1325-1347.

21. Zargari A. Medicinal Plants, p. 136. Tehran University Publishing, Tehran, 1997. 
22. Andalib S, Vaseghi A, Vaseghi G, Naeini AM. Sedative and hypnotic effects of Iranian traditional medicinal herbs used for treatment of insomnia. EXCLI J 2011;10:192-197.

23. Rabbani MVG, Sajjadi SE. Persian herbal medicines with anxiolytic properties. J Med Plants 2011;39:7-11.

24. Merzouki A, Ed-derfoufi F, Molero Mesa J. Contribution to the knowledge of Rifian traditional medicine. II: Folk medicine in Ksar Lakbir district (NW Morocco). Fitoterapia 2000;71:278-307.

25. Latha K, Rammohan B, Sunanda BP, Maheswari MS, Mohan SK. Evaluation of anxiolytic activity of aqueous extract of Coriandrum sativum Linn. in mice: a preliminary experimental study. Pharmacognosy Res 2015;7:S47-S51.

26. Cachat J, Stewart A, Grossman L, Gaikwad S, Kadri F, Chung $\mathrm{KM}$, et al. Measuring behavioral and endocrine responses to novelty stress in adult zebrafish. Nat Protoc 2010;5:1786-1799.

27. Canzian J, Fontana BD, Quadros VA, Rosemberg DB. Conspecific alarm substance differently alters group behavior of zebrafish populations: putative involvement of cholinergic and purinergic signaling in anxiety- and fearlike responses. Behav Brain Res 2017;320:255-263.

28. Speedie N, Gerlai R. Alarm substance induced behavioral responses in zebrafish (Danio rerio). Behav Brain Res 2008;188:168-177.

29. Egan RJ, Bergner CL, Hart PC, Cachat JM, Canavello PR, Elegante MF, et al. Understanding behavioral and physiological phenotypes of stress and anxiety in zebrafish. Behav Brain Res 2009;205:38-44.

30. Quadros VA, Silveira A, Giuliani GS, Didonet F, Silveira AS, Nunes ME, et al. Strain- and context-dependent behavioural responses of acute alarm substance exposure in zebrafish. Behav Processes 2016;122:1-11.

31. Alfaro JM, Ripoll-Gomez J, Burgos JS. Kainate administered to adult zebrafish causes seizures similar to those in rodent models. Eur J Neurosci 2011;33:1252-1255.

32. Kinkel MD, Eames SC, Philipson LH, Prince VE. Intraperitoneal injection into adult zebrafish. J Vis Exp 2010.

33. Maximino C, Marques de Brito T, Dias CA, Gouveia A, Jr., Morato S. Scototaxis as anxiety-like behavior in fish. Nat Protoc 2010;5:209-216.

34. Maximino C, da Silva AW, Gouveia A, Jr., Herculano AM. Pharmacological analysis of zebrafish (Danio rerio) scototaxis. Prog Neuropsychopharmacol Biol Psychiatry 2011;35:624-631.

35. Rosemberg DB, Rico EP, Mussulini BH, Piato AL, Calcagnotto $\mathrm{ME}$, Bonan $\mathrm{CD}$, et al. Differences in spatiotemporal behavior of zebrafish in the open tank paradigm after a short-period confinement into dark and bright environments. PLoS One 2011;6:e19397.

36. Nunes ME, Muller TE, Braga MM, Fontana BD, Quadros VA, Marins A, et al. Chronic treatment with paraquat induces brain injury, changes in antioxidant defenses system, and modulates behavioral functions in zebrafish. Mol Neurobiol 2016.

37. Wong K, Elegante M, Bartels B, Elkhayat S, Tien D, Roy S, et al. Analyzing habituation responses to novelty in zebrafish (Danio rerio). Behav Brain Res 2010;208:450-457.

38. Jesuthasan SJ, Mathuru AS. The alarm response in zebrafish: innate fear in a vertebrate genetic model. J Neurogenet 2008;22:211-228.

39. Kalueff AV, Gebhardt M, Stewart AM, Cachat JM, Brimmer M, Chawla JS, et al. Towards a comprehensive catalog of zebrafish behavior 1.0 and beyond. Zebrafish 2013;10:70-86.

40. Bencan Z, Sledge D, Levin ED. Buspirone, chlordiazepoxide and diazepam effects in a zebrafish model of anxiety. Pharmacol Biochem Behav 2009;94:75-80.
41. Ibrahim M, Mussulini BH, Moro L, de Assis AM, Rosemberg DB, de Oliveira DL, et al. Anxiolytic effects of diphenyl diselenide on adult zebrafish in a novelty paradigm. Prog Neuropsychopharmacol Biol Psychiatry 2014;54:187-194.

42. Gebauer DL, Pagnussat N, Piato AL, Schaefer IC, Bonan CD, Lara DR. Effects of anxiolytics in zebrafish: similarities and differences between benzodiazepines, buspirone and ethanol. Pharmacol Biochem Behav 2011;99:480-486.

43. Jabeen Q, Bashir S, Lyoussi B, Gilani AH. Coriander fruit exhibits gut modulatory, blood pressure lowering and diuretic activities. J Ethnopharmacol 2009;122:123-130.

44. Zargar-Nattaj SS, Tayyebi P, Zangoori V, Moghadamnia Y, Roodgari H, Jorsaraei SG, et al. The effect of Coriandrum sativum seed extract on the learning of newborn mice by electric shock: interaction with caffeine and diazepam. Psychol Res Behav Manag 2011;4:13-19.

45. Ishikawa T, Kondo K, Kitajima J. Water-soluble constituents of coriander. Chem Pharm Bull (Tokyo) 2003;51:32-39.

46. Abdalla FH, Schmatz R, Cardoso AM, Carvalho FB, Baldissarelli J, de Oliveira JS, et al. Quercetin protects the impairment of memory and anxiogenic-like behavior in rats exposed to cadmium: possible involvement of the acetylcholinesterase and $\mathrm{Na}(+), \mathrm{K}(+)$-ATPase activities. Physiol Behav 2014;135:152-167.

47. Bhutada P, Mundhada Y, Bansod K, Ubgade A, Quazi M, Umathe $\mathrm{S}$, et al. Reversal by quercetin of corticotrophin releasing factor induced anxiety- and depression-like effect in mice. Prog Neuropsychopharmacol Biol Psychiatry 2010;34:955-960.

48. Kumar A, Goyal R. Quercetin protects against acute immobilization stress-induced behaviors and biochemical alterations in mice. J Med Food 2008;11:469-473.

49. Kawabata K, Kawai Y, Terao J. Suppressive effect of quercetin on acute stress-induced hypothalamic-pituitary-adrenal axis response in Wistar rats. J Nutr Biochem 2010;21:374-380.

50. Merzoug S, Toumi ML, Tahraoui A. Quercetin mitigates Adriamycin-induced anxiety- and depression-like behaviors, immune dysfunction, and brain oxidative stress in rats. Naunyn Schmiedebergs Arch Pharmacol 2014;387:921-933.

51. Maciel RM, Carvalho FB, Olabiyi AA, Schmatz R, Gutierres JM, Stefanello N, et al. Neuroprotective effects of quercetin on memory and anxiogenic-like behavior in diabetic rats: role of ectonucleotidases and acetylcholinesterase activities. Biomed Pharmacother 2016;84:559-568.

52. Wang XH, Zhang CX, Li GY, Huang JM, Zhai HF. [Review on anxiolytic effect of natural small-molecule phenols]. Zhongguo Zhong Yao Za Zhi 2017;42:1557-1565.

53. Fedotova J, Kubatka P, Busselberg D, Shleikin AG, Caprnda $\mathrm{M}$, Dragasek J, et al. Therapeutical strategies for anxiety and anxiety-like disorders using plant-derived natural compounds and plant extracts. Biomed Pharmacother 2017;95:437-446.

Address correspondence to: Kamila Cagliari Zenki, PhD Laboratory of Cellular Neurochemistry Department of Biochemistry Instituto de Ciências Básicas da Saúde Universidade Federal do Rio Grande do Sul Rua Ramiro Barcelos 2600 - Anexo Porto Alegre - RS 90035-003 Brazil

E-mail: kamizenki@gmail.com 